\title{
An Ecofriendly and Stability-Indicating HPLC Method for Determination of Permethrin Isomers: Application to Pharmaceutical Analysis
}

\author{
Minoo Afshar, ${ }^{1}$ Niloufar Salkhordeh, ${ }^{1,2}$ and Mehdi Rajabi ${ }^{2}$ \\ ${ }^{1}$ Department of Pharmaceutics, Pharmaceutical Sciences Branch, Islamic Azad University (IAUPS), Tehran 193956466, Iran \\ ${ }^{2}$ Department of Clinical Pharmacy, Pharmaceutical Sciences Branch, Islamic Azad University (IAUPS), Tehran 193956466, Iran \\ Correspondence should be addressed to Minoo Afshar; afsharme@sina.tums.ac.ir
}

Received 8 June 2012; Revised 28 July 2012; Accepted 2 August 2012

Academic Editor: Victor David

Copyright ( $\odot 2013$ Minoo Afshar et al. This is an open access article distributed under the Creative Commons Attribution License, which permits unrestricted use, distribution, and reproduction in any medium, provided the original work is properly cited.

A green, simple, and stability-indicating RP-HPLC method was developed for simultaneous determination of permethrin isomers in pharmaceutical preparations. The separation was based on a $\mathrm{C}_{18}$ analytical column $(150 \times 4.6 \mathrm{~mm}$, i.d., $5 \mu \mathrm{m})$. The mobile phase consisted of ethanol: phosphoric acid solution $(\mathrm{pH}=3)(67: 33, \mathrm{v} / \mathrm{v})$. The elution was carried out at $30^{\circ} \mathrm{C}$ temperature with a flow rate of $1.0 \mathrm{~mL} / \mathrm{min}$. Quantitation was achieved with UV detection at $215 \mathrm{~nm}$. In forced degradation studies, the drug was subjected to oxidation, hydrolysis, photolysis, and heat. The method was validated for specificity, linearity, precision, accuracy, and robustness. The applied procedure was found to be linear in permethrin concentration range of $0.5-50 \mu \mathrm{g} / \mathrm{mL}$ with correlation coefficients of 0.9996 for each isomer. Precision was evaluated by replicate analysis in which \% relative standard deviation (RSD) values for areas were found below 2.0. The recoveries obtained (99.24\%-100.72\%) ensured the accuracy of the developed method. The peaks of permethrin isomers well resolved from various degradation products as well as the pharmaceutical excipients. Accordingly, the proposed validated and sustainable procedure was proved to be proper for routine analyzing and stability studies of permethrin in pharmaceutical preparations.

\section{Introduction}

Permethrin, ( \pm )-3-phenoxybenzyl 3-(2,2-dichlorovinyl)-2,2dimethylcyclopropanecarboxylate (Figure 1), is a synthetic mixture of cis- and trans-isomers of pyrethrin, chemically altered to bestow light and heat stability [1]. Permethrin isomers have different chemical, physical, and toxicological properties. It has been reported that the toxicity of permethrin with a cis-:trans- ratio of $25: 75$ is lower than that of permethrin with a cis-: trans- ratio of $40: 60$. This drug acts on the nervous system of insects and interferes with sodium channels to disrupt the function of neurons, and causes muscles to spasm, culminating in paralysis, and death [2-4]. Permethrin is used predominantly for treatment of scabies, caused by head lice and mites $[5,6]$. Recently, studies have demonstrated the efficacy of permethrin therapy in the treatment of acne rosacea for its mite eradicating ability [7-10]. Moreover, it has been used as ectoparasiticides in agriculture, in the impregnation of clothing, and also in veterinary medicine, since pyrethroids development in the 1970s [11].

Concerning new therapeutic application of permethrin, validated and stability-indicating methods should be available to determine this drug in topical preparations. However, no method was compiled in British and United state pharmacopoeias for the analysis of this medicine in pharmaceutical preparations. Few methods reported the quantitation of permethrin in pharmaceutical dosage forms using spectrophotometric methods, [12] and LC methods with ultraviolet detection [13-16], most of which have not been validated according to International Conference on Harmonization (ICH) stability-indicating guidelines.

In all of the aforementioned LC techniques, acetonitrile or methanol has been used as a part of mobile phase or extraction procedure. It is worth mentioning that these solvents are ranked by US Environmental Protection Agency (EPA) as 
<smiles>CC1(C)[C@H](C=C(Cl)Cl)[C@H]1C(=O)OCc1cccc(Oc2ccccc2)c1</smiles>

(a)

(b)

FIgURE 1: Molecular structures of (a) trans- and (b) cis-permethrin.

hazardous solvents [17] and because of their inherent toxicity [18], safe detoxification of the waste solvents is essential, which may lead to high to very high disposal costs.

Due to scientific and public concern about the environment pollution, environmentally friendly practices have been introduced in different areas of society and research. In green analytical chemistry, sample preparation and LC analysis need special attention because hazardous solvents, are often used. Possibilities toward green LC include reducing solvent use, switching to more benign solvents and/or eliminating organic solvents [19-23].

Taking ICH guidelines in consideration, the present study describes a simple, validated, and stability-indicating analytical method for determination of permethrin isomers, which meets the green aspects in analytical chemistry. The performances of the method were evaluated, and its potential for the determination of permethrin isomers in pharmaceutical preparations was investigated.

\section{Experimental Section}

2.1. Materials, Reagents, and Chemicals. Qualified permethrin standard (99.88\%) was kindly provided by Gilaranco (Rasht, Iran). All solvents and reagents were of gradient and analytical grade, respectively, and were purchased from Merck (Darmstadt, Germany). HPLC grade water was obtained through a Milli-Q system (Millipore, Milford, MA, USA) and was used to prepare all solutions. The pharmaceutical formulations (cream 5\%) and the corresponding placebos (mixture of all the excipients) were prepared in our laboratory. Permethrin cream 5\% manufactured by Gilaranco (Rasht, Iran) was purchased from local pharmacy.

2.2. Equipments. The HPLC method was carried out on a Shimadzu HPLC system (Shimadzu, Kyoto, Japan), set to recycle the mobile phase and was equipped with an SCL10AVP system controller, LC-10 ADVP pump, DGU-14A degasser, and a SPD-M10AVP PDA detector. The peak areas were integrated automatically by computer using a Shimadzu Class VP software program. A $20 \mu \mathrm{L}$ volume of sample was introduced into a Rheodyne model $7725 \mathrm{i}$ injector.

2.3. Chromatographic Conditions. The elution was carried out on a $\mathrm{C}_{18}$ column $(150 \mathrm{~mm} \times 4.6 \mathrm{~mm}, 5 \mu \mathrm{m}$ particle size) from Teknokroma (Barcelona, Spain). All analyses were performed at the column temperature of $30 \pm 1^{\circ} \mathrm{C}$ under isocratic conditions with a mobile phase of ethanol: phosphoric acid solution $(\mathrm{pH}=3.0)(67: 33, \mathrm{v} / \mathrm{v})$, and a flowrate of $1.0 \mathrm{~mL} / \mathrm{min}$, using PDA detection at $215 \mathrm{~nm}$.

2.4. Preparation of Standard Solutions. Stock standard solution of permethrin was prepared in ethanol $96 \%$ at a concentration of $10 \mathrm{mg} / \mathrm{mL}$. This solution was found to be stable for at least 1 month, when stored at $2-8^{\circ} \mathrm{C}$. Freshly prepared working standards at concentration levels of $0.5,2,5,10$, 20 , and $50 \mu \mathrm{g} / \mathrm{mL}$ were obtained from stock solution by the appropriate dilution in HPLC-grade water.

2.5. Preparation of Test Solutions. A 1 gr portion of cream (equivalent to $50 \mathrm{mg}$ of permethrin) was transferred into a $100 \mathrm{~mL}$ volumetric flask. The volume was adjusted to the mark with ethanol $96 \%$ to provide a theoretical concentration of $500 \mu \mathrm{g} / \mathrm{mL}$ of permethrin. The solution was serial diluted with HPLC-grade water to make final concentration of $9 \mu \mathrm{g} / \mathrm{mL}$. The experiment was performed in triplicate. These samples were assayed using calibration curves of working standard solutions. The same procedure was applied to placebo to be sure about the selectivity of the method.

2.6. Method Development. A variety of mobile phases were investigated in the development of a stability-indicating LC method for the analysis of permethrin isomers in pharmaceutical preparations. The suitability of mobile phase was decided on the basis of green analytical chemistry principles, selectivity, and sensitivity of the assay, stability studies, and separation of permethrin isomers from the impurities formed during forced degradation studies. Different wavelengths were also investigated.

2.7. Forced Degradation Studies. The stability-indicating capability of the method was determined by subjecting reference solutions $(50 \mu \mathrm{g} / \mathrm{mL})$ to accelerated degradation by acidic, basic, heat, oxidative, and photolytic conditions to evaluate the interferences in the quantitation of permethrin isomers. Sample solutions prepared in $1 \mathrm{M}$ hydrochloric acid and $1 \mathrm{M}$ sodium hydroxide were used for the acidic and basic hydrolysis, respectively. Both solutions were kept at ambient temperature for $12 \mathrm{~h}$ and then neutralized with basic or acidic 
solutions, as necessary. For evaluating the heat condition, the reference solution heated at $80^{\circ} \mathrm{C}$ for $12 \mathrm{~h}$. For oxidative degradation, sample solutions were prepared in a solution of hydrogen peroxide (3\%) and kept at ambient temperature for $4 \mathrm{~h}$, protected from light. Photodegradation was induced by exposing the sample solution to UV-Lamp at a wavelength of $254 \mathrm{~nm}$ placed in a wooden cabinet for 1 hour. The solutions were diluted with HPLC-grade water to final concentration of $10 \mu \mathrm{g} / \mathrm{mL}$ and were injected into chromatograph.

2.8. Method Validation. The developed method was validated as per the requirements of the ICH guidelines. Linearity was evaluated by determining six working standard solutions at a concentration range of $0.5-50 \mu \mathrm{g} / \mathrm{mL}$. Five sets of such solutions were prepared. Each set was analyzed to plot a calibration curve. Slope, intercept, and coefficient of determination $\left(r^{2}\right)$ of the calibration curves were calculated to ascertain linearity of the method. The limit of quantification (LOQ) was defined as the lowest concentrations with the RSDs lower than $5 \%$ and accuracies within $\pm 5 \%$, considering at least seven times the response compared to that of the blank. In order to check the robustness, the effect of small but deliberate variations in the chromatographic conditions was evaluated. The conditions studied were flow rate (altered by $\pm 0.2 \mathrm{~mL} / \mathrm{min}$ ), column temperature (altered by $\pm 2^{\circ} \mathrm{C}$ ), and $\mathrm{pH}$ of phosphoric acid solution (altered by \pm 0.2 ). These chromatographic variations were evaluated for resolution between permethrin isomers and \% assay of the drug. For method repeatability, assay of working standard solutions $(0.5,10,20$ and $50 \mu \mathrm{g} / \mathrm{mL})$ was repeatedly performed five times on the same day (intraday). For reproducibility, freshly prepared solutions at aforementioned concentration levels were analyzed at different days (interday), and results were statistically evaluated in terms of \% RSD. For recovery studies, 0.5 gr portions of preassayed permethrin cream $5 \%$ were spiked with extra 1, 2, and $4 \mathrm{~mL}$ of stock standard solution. These samples were handled as explain in Section 2.5, and the final target levels of 7,9 , and $13 \mu \mathrm{g} / \mathrm{mL}$ were prepared. The concentrations were calculated using calibration curves. Accuracy was calculated as the deviation of the mean from nominal concentration. To assess accuracy, freshly prepared placebo of the permethrin pharmaceutical formulations was spiked with various amounts of permethrin to obtain the concentration levels of $0.5,10,20$, and $50 \mu \mathrm{g} / \mathrm{mL}$. Each solution was injected in triplicate. Selectivity of this method was indicated by the absence of any excipient interference at retention times of the peaks of permethrin isomers. The absence of interfering peak was evaluated by injecting a blank sample consisting of diluent and placebo. The double check of the lack of interferences of the resulting by-products with the elution of the peaks of permethrin isomers was done by calculating the F factor, meaning the ratio of the UV molar absorption coefficients of permethrin isomers at the $215 \mathrm{~nm}$ and $272 \mathrm{~nm}$, respectively, using (1)

$$
F=\frac{\mathrm{A}(215)}{\mathrm{A}(272)}
$$

where A (215) and A (272) are the permethrin peaks areas obtained at $215 \mathrm{~nm}$ and $272 \mathrm{~nm}$, respectively. The resulting F factors were compared with those of the standards [24].

2.9. Estimation of the Uncertainty of the Measurements. An expanded uncertainty budget was constructed for permethrin isomers in pharmaceutical preparations by the RPHPLC-DAD method according to previously reported procedures [25-28].

Four individual sources were taken into account to assess the expanded uncertainty.

2.9.1. Uncertainty of the Measurement Standard. The uncertainty of the measurement standard is calculated by the quadratic addition of two terms: the uncertainty certified by manufacturer $\left(U_{\text {stock }}\right)$ and the uncertainty corresponding to its preparation by dilution or weighting $\left(U_{\text {preparation }}\right)(2)$ [25].

$$
U_{\text {standard }}(\%)=\sqrt{U_{\text {stock }}^{2}(\%)+U_{\text {preparation }}^{2}(\%)} .
$$

The stock uncertainty $\left(U_{\text {stock }}\right)$ is calculated from a value given by the manufacturer using

$$
U_{\text {stock }}(\%)=\frac{(100-P \%)}{\sqrt{3}},
$$

where the purity is expressed as $P \%$. When there are independent standard preparations at each concentration level, the $U_{\text {preparation }}$ term could be eliminated. In this case, the contribution of this term is included in the $U_{\text {precision }}$ term $[25,26]$.

2.9.2. Uncertainty Associated to the Calibration Curve. This value is calculated using (4) [27].

$$
U_{\text {calibration }}=\frac{s_{x_{0}}}{x_{0}}
$$

where $x_{0}$ is the concentration calculated from the calibration curve and $s_{x_{0}}$ is the standard deviation of the concentration, calculated from the calibration curve using

$$
\begin{gathered}
s_{x_{0}}=\frac{s(r)}{m} \sqrt{\frac{1}{N}+\frac{1}{n}+\frac{\left(\bar{Y}_{0}-\bar{Y}\right)^{2}}{m^{2} \sum_{i=1}^{n}\left(x_{i}-\bar{x}\right)^{2}}}, \\
s(r)=\sqrt{\frac{\sum\left(y_{i}-m x_{i}-b\right)^{2}}{n-2}},
\end{gathered}
$$

where $m$ is the slope of the line, $b$ is the $y$-intercept of the line, $N$ is the number of replicate unknowns, $n$ is the number of the standards, $\bar{Y}_{0}$ is the mean of $N$ repeat measurements of $y$ for the sample, $\bar{Y}$ is the mean of the $y$ values for the calibration standards, $x_{i}$ are the concentrations of the standards, $\bar{x}$ is the average concentration of the standards.

2.9.3. Uncertainty Associated to Precision. This value is calculated using

$$
U_{\text {precision }}=\frac{s}{x_{0 \sqrt{n}}}
$$


where $s$ is standard deviation of the experimental data for precision and $n$ is the number of assays [27].

2.9.4. Uncertainty Associated to Accuracy. This parameter is calculated using

$$
U_{\text {accuracy }}=\frac{s(\eta)}{\sqrt{n}},
$$

$s(\eta)$ is the relative standard deviation of the recovery and $n$ is the number of assays [27].

The value of the expanded uncertainty was calculated according to ISO GUM guidelines using

$$
U=k c \sqrt{U_{\text {standard }}^{2}+U_{\text {calibration }}^{2}+U_{\text {precision }}^{2}+U_{\text {accuracy }}^{2}},
$$

where $U$ is expanded uncertainty, $k$ the coverage factor (for confidence interval 95\%, $k=2$ ), $c$ is the concentration of the drug [28].

\section{Results and Discussion}

3.1. Optimization of the Chromatographic Conditions. Optimum conditions, which are necessary for the quantitative analysis of the permethrin isomers with maximum sensitivity, were established by a number of preliminary experiments. In this context, different detection wavelengths and compositions of mobile phase, considering the green chemistry principles [18] were explored. Optimum conditions were fixed by varying one parameter at a time while fixing other parameters constant and observing its effect on the peak resolution and also on the response.

Initially, ethanol was replaced with acetonitrile in mobile phase previously reported containing acetonitrile: water $(70: 30, \mathrm{v} / \mathrm{v})[29]$, in order to use a benign and green solvent. Although ethanol has some shared or similar characteristics to methanol and acetonitrile, some properties are different. By nature, ethanol has twice the viscosity of methanol, and almost 4 times the viscosity of acetonitrile. In addition, it has different strength of the solvents. Thus, the mobile phase composition as well as the operating conditions needed to be optimized. The aforementioned change in mobile phase resulted in unresolved permethrin isomers appearing before 12 minutes. In an attempt to improve separation, ethanol content of mobile phase were decreased, and the resolution values of higher than 2 was achieved with the ratio of $65: 35$. But in this situation, the peak shapes and retention times were not satisfactory. Decreasing the $\mathrm{pH}$ of water to 3.0 using phosphoric acid solution helped to reduce the retention times and to sharpen the peaks. The chromatograms related to the above procedures are shown in Figure 2. According these preliminary results, the detection wavelength of $215 \mathrm{~nm}$ and the mobile phase of ethanol: phosphoric acid solution $(\mathrm{pH}=$ 3) $(67: 33, v / v)$ were finalized. Under such chromatographic condition, trans- and cis-isomers separated adequately and appeared at 16.2 and $20.3 \mathrm{~min}$, respectively, (Figure 3(a)). Before fully implemented in the quantitative determination of drug substance and pharmaceutical preparation, this method was thoroughly validated according to ICH guidelines.
TABLE 1: Summary of stress degradation studies of permethrin isomers.

\begin{tabular}{lccc}
\hline $\begin{array}{l}\text { Stress condition/ } \\
\text { media/duration }\end{array}$ & $\begin{array}{c}\text { Recovered } \\
\text { trans-isomer } \\
(\%)\end{array}$ & $\begin{array}{c}\text { Recovered } \\
\text { cis-isomer } \\
(\%)\end{array}$ & $\begin{array}{c}\text { Number of } \\
\text { unknown } \\
\text { impurities }\end{array}$ \\
\hline $\begin{array}{l}\text { Photolytic } / \mathrm{H}_{2} \mathrm{O} / \\
254 \mathrm{~nm} / 1 \mathrm{~h}\end{array}$ & 98.69 & 98.06 & 0 \\
Acidic $/ 1.0 \mathrm{~N} \mathrm{HCl} / 12 \mathrm{~h}$ & 68.08 & 64.57 & 4 \\
Neutral $/ \mathrm{H}_{2} \mathrm{O} / 80^{\circ} \mathrm{C} / 12 \mathrm{~h}$ & 96.80 & 97.54 & 1 \\
$\begin{array}{l}\text { Oxidative } / 3.0 \% \\
\mathrm{H}_{2} \mathrm{O}_{2} / 4 \mathrm{~h}\end{array}$ & 88.05 & 84.76 & 0 \\
Basic $/ 1.0 \mathrm{~N} \mathrm{NaOH} / 12 \mathrm{~h}$ & 0.00 & 0.00 & 3 \\
\hline
\end{tabular}

3.2. Forced Degradation Studies. Stability-indicating method is defined as an analytical method that accurately quantifies the active ingredients without interference from degradation products, process impurities, excipients, or other potential impurities [30]. The forced degradation studies in photolytic condition, resulted in nonsignificant decrease of the area without any detectable eluting degradation product (Figure 3(f)). However, under the acidic condition, permethrin isomers exhibited a significant decrease, in that only $68.08 \%$ of trans- and $64.57 \%$ of cis-isomers were recovered and four additional hydrophilic peaks were detected before $6 \mathrm{~min}$ (Figure 3(c)). The heat condition also exhibited decrease of the areas to $96.80 \%$ and $97.54 \%$ for trans- and cisisomers, respectively, and presumably only one peak was detected, which eluted in solvent front (Figure 3(b)). Under the oxidative condition, the trans- and cis-isomer contents decreased to $88.05 \%$ and $84.76 \%$, respectively, without any additional peak (Figure 3(e)), indicating that the degradation products did not elute in the HPLC method or may have been degraded to nonchromophoric products. As reported previously [15], permethrin isomers were degraded thoroughly under alkaline condition, and three additional peaks were observed before $6 \mathrm{~min}$ (Figure 3(d)). Summary of all degradation studies is mentioned in Table 1.

\subsection{Method Validation}

3.3.1. Selectivity and Specificity. The application of the whole procedure to placebo samples in order to verify the method selectivity demonstrates that no interferences were detected (Figure 4(b)). The specificity of the method was illustrated by the complete separation of permethrin isomers from each other and from different degradation products as shown in Figure 3. Furthermore, the decreases observed in isomer contents in stability studies, when degradation products appeared, proved the specificity of the method (Table 1). Also, the $\mathrm{F}$ factors of the permethrin isomers in stress solutions [(15.70-15.90), (15.43-15.74)] show the same values of that of the standards $(15.80,15.58)$ for trans- and cis-isomers, respectively.

3.3.2. Linearity, Precision and LOQ. Linearity was determined by constructing five independent calibration curves each one with six calibration points of permethrin, including 


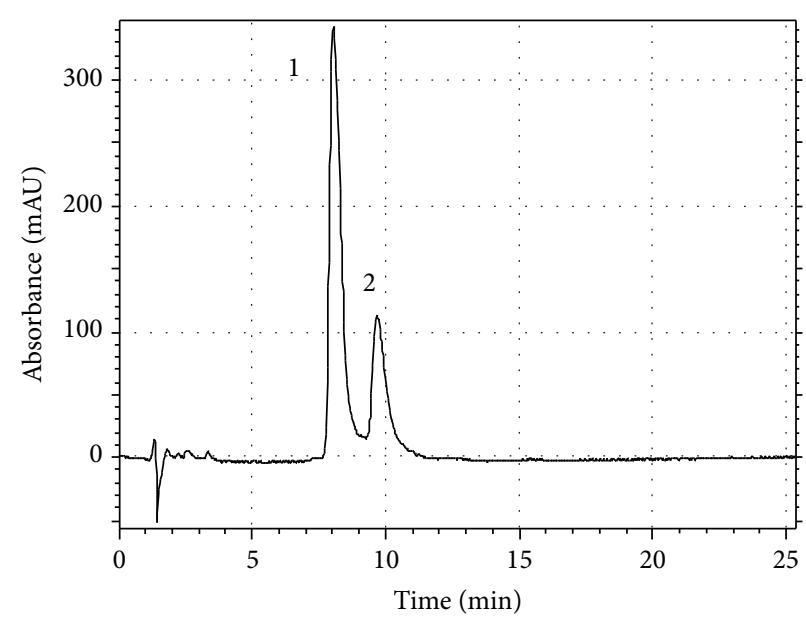

(a)

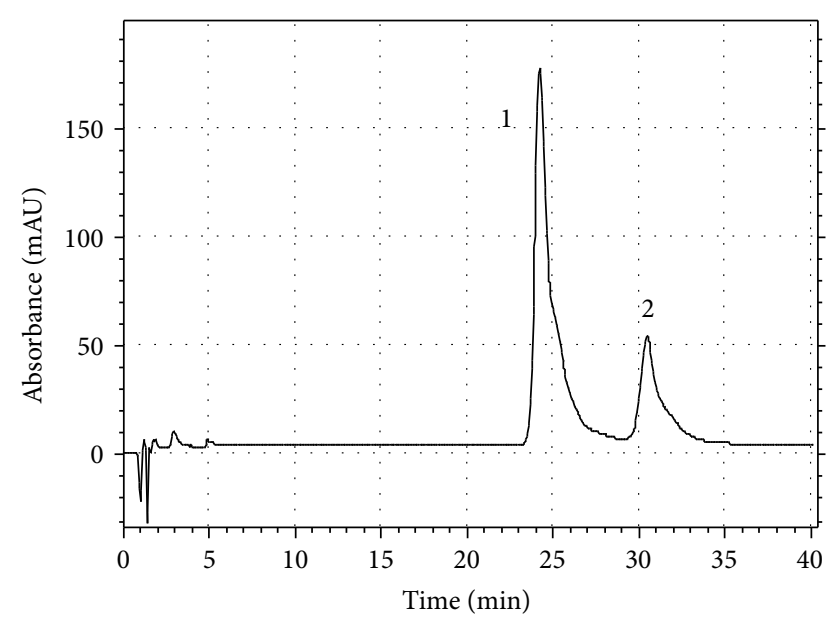

(b)

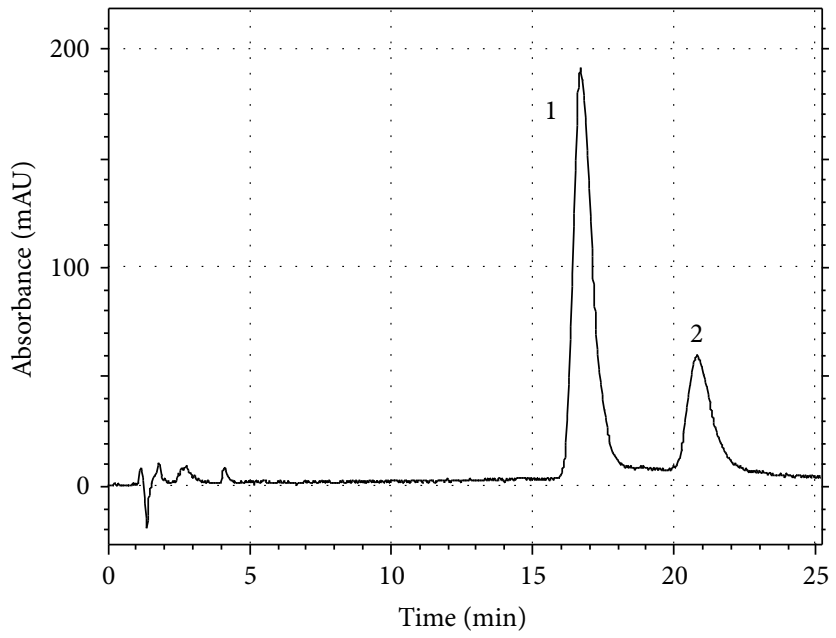

(c)

FIGURE 2: Chromatograms of permethrin obtained using the mobile phase, consisting of: (a) ethanol : water (70:30, v/v); (b) ethanol: water $(65: 35, \mathrm{v} / \mathrm{v})$ and $(\mathrm{c})$ ethanol : phosphoric acid solution $(\mathrm{pH}=3)(67: 33, \mathrm{v} / \mathrm{v})$. Peak $1=$ trans-, peak $2=$ cis-isomers.

TABLE 2: Precision, accuracy, and recovery data for the proposed method.

\begin{tabular}{|c|c|c|c|c|c|c|c|c|}
\hline \multirow[b]{2}{*}{ Isomers } & \multirow[b]{2}{*}{$\begin{array}{l}\text { Permethrin } \\
\text { concentration } \\
(\mu \mathrm{g} / \mathrm{mL})\end{array}$} & \multicolumn{2}{|c|}{ Precision (RSD, \%) } & \multirow[b]{2}{*}{$\begin{array}{c}\text { Accuracy } \\
(n=3) \\
\text { mean (RSD, \%) }\end{array}$} & \multicolumn{4}{|c|}{ Recovery $(n=3)$} \\
\hline & & $\begin{array}{c}\text { Intraday } \\
(n=5)\end{array}$ & $\begin{array}{c}\text { Interday } \\
(n=5)\end{array}$ & & $\begin{array}{c}\text { Target } \\
\text { concentration } \\
(\mu \mathrm{g} / \mathrm{mL})\end{array}$ & $\begin{array}{c}\text { Calculated } \\
\text { concentration } \mu \mathrm{g} / \mathrm{mL} \\
(\text { mean })\end{array}$ & $\%$ & $\pm \mathrm{SD}$ \\
\hline \multirow{4}{*}{ Trans- } & 0.50 & 1.85 & 2.07 & $100.94(2.90)$ & 7.0 (5.25 as trans) & 5.21 & 99.24 & 0.03 \\
\hline & 10.00 & 0.94 & 1.30 & $101.00(0.43)$ & 9.0 (6.75 as trans $)$ & 6.71 & 99.41 & 0.09 \\
\hline & 20.00 & 0.84 & 1.78 & $101.28(0.55)$ & $13.0(9.75$ as trans $)$ & 9.82 & 100.72 & 0.14 \\
\hline & 50.00 & 0.73 & 1.80 & $99.53(0.14)$ & & & & \\
\hline \multirow{4}{*}{ Cis- } & 0.500 & 1.90 & 1.94 & $101.42(2.20)$ & $7.0(1.75$ as cis $)$ & 1.75 & 100.00 & 0.03 \\
\hline & 10.00 & 0.70 & 1.90 & $101.23(0.47)$ & $9.0(2.25$ as cis $)$ & 2.26 & 100.44 & 0.04 \\
\hline & 20.00 & 1.10 & 1.22 & $99.58(1.98)$ & $13.0(3.25$ as cis $)$ & 3.24 & 99.69 & 0.03 \\
\hline & 50.00 & 1.02 & 1.91 & $99.96(0.43)$ & & & & \\
\hline
\end{tabular}




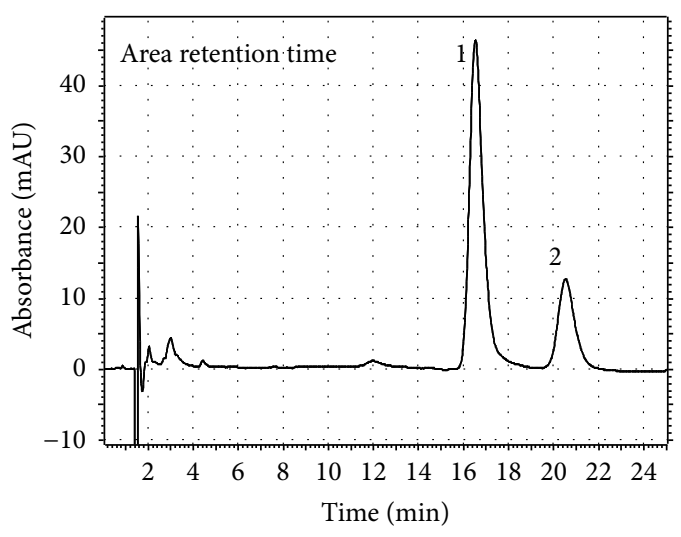

— 1: $215 \mathrm{~nm}, 8 \mathrm{~nm}$ permethrin-vreal-10.dat

(a)

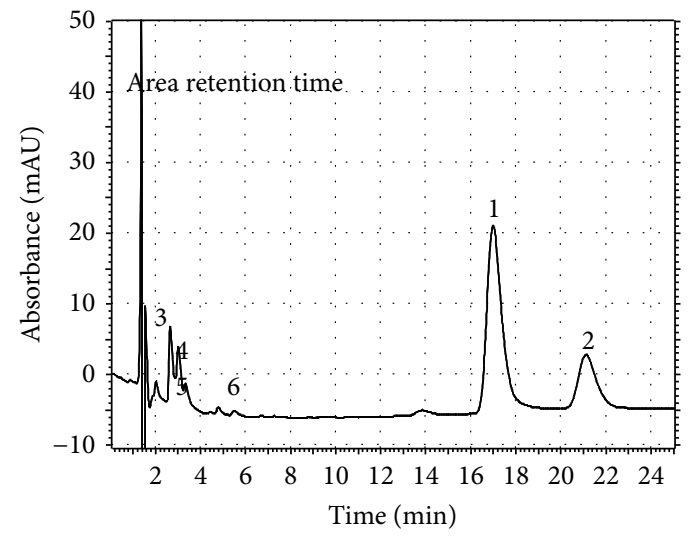

— 1: $215 \mathrm{~nm}, 8 \mathrm{~nm}$ permethrin-vr-acid10.dat

(c)

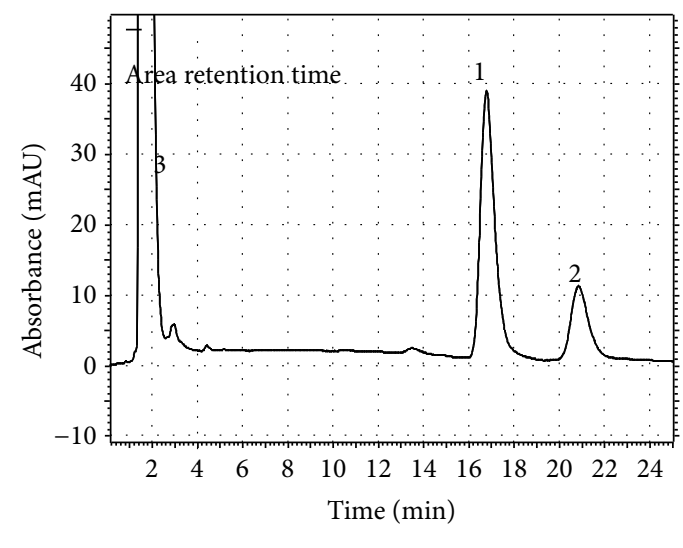

1: $215 \mathrm{~nm}, 8 \mathrm{~nm}$ permethrin-v-h2o210.dat

(e)

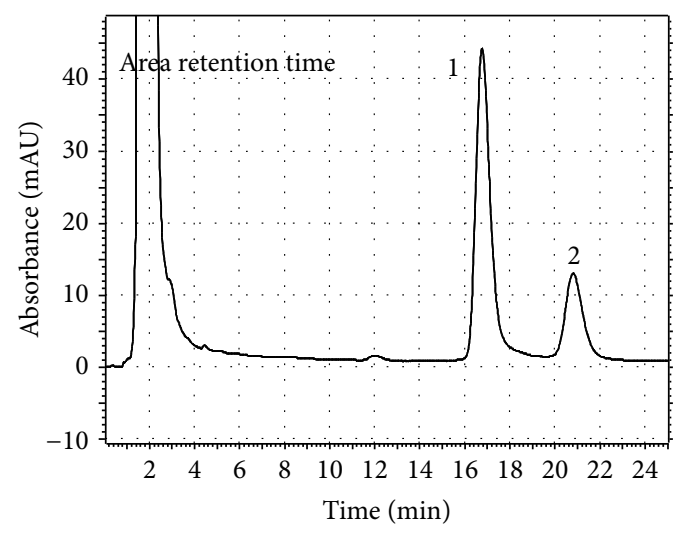

— 1: $215 \mathrm{~nm}, 8 \mathrm{~nm}$ permethrin-vrwater-10.dat

(b)

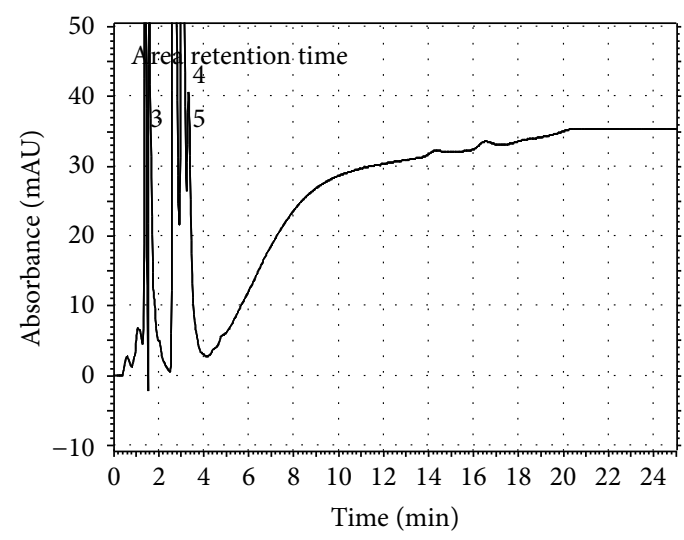

1: $215 \mathrm{~nm}, 8 \mathrm{~nm}$ permethrin-v-naoh-10.dat

(d)

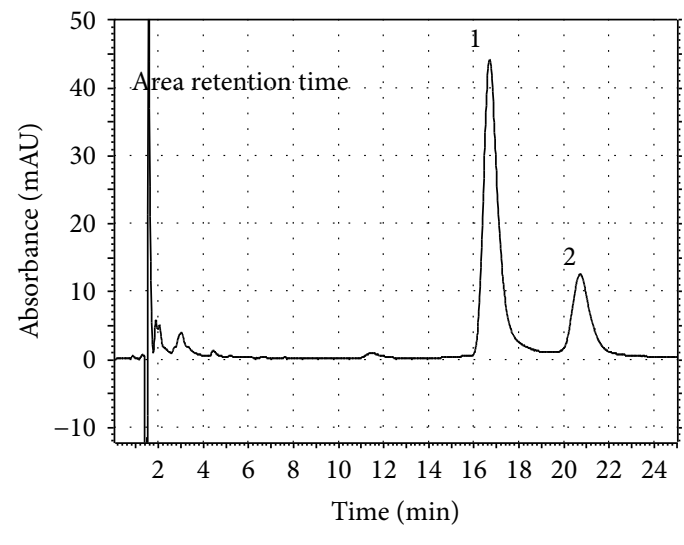

— $1: 215 \mathrm{~nm}, 8 \mathrm{~nm}$ permethrin-v-uv.dat

(f)

FIGURE 3: Typical chromatograms of: (a) permethrin working standard solution $(10 \mu \mathrm{g} / \mathrm{mL})$ and after degradation under: (b) heat condition; (c) acidic hydrolysis: peaks 3, 4, 5, and 6 = degraded forms; (d) basic hydrolysis: peaks 3, 4, and 5 degraded forms; (e) oxidative condition: peak 3 = hydrogen peroxide; (f) photolytic condition: Peak $1=$ trans-, peak $2=$ cis-isomers.

the LOQ, in the range of $0.5-50$ (sum of isomers) $\mu \mathrm{g} / \mathrm{mL}$. The peak area of each isomer against the respective concentration was used for plotting the graph considering the ratio of trans-: cis- as $3: 1$, and the linearity evaluated by the least square regression analysis. The linearity curves were defined by the following equation for trans-isomer: $y=225965 x+43623$, and $y=220640 x+9149.9$ for cisisomer. The value of the determination coefficient calculated $\left(r^{2}=0.9996\right.$ for each isomer) indicated the linearity of the calibration curve for the method. Moreover, the relative 


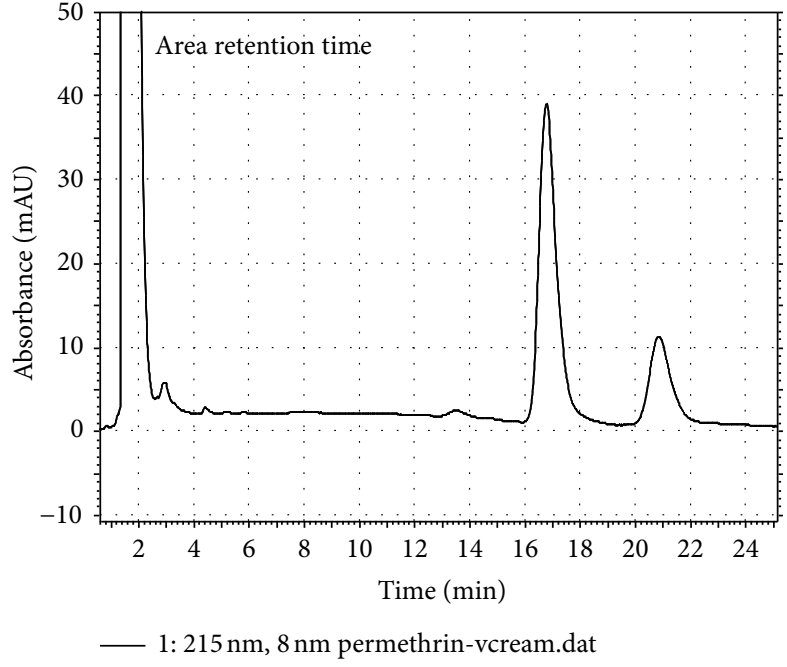

(a)

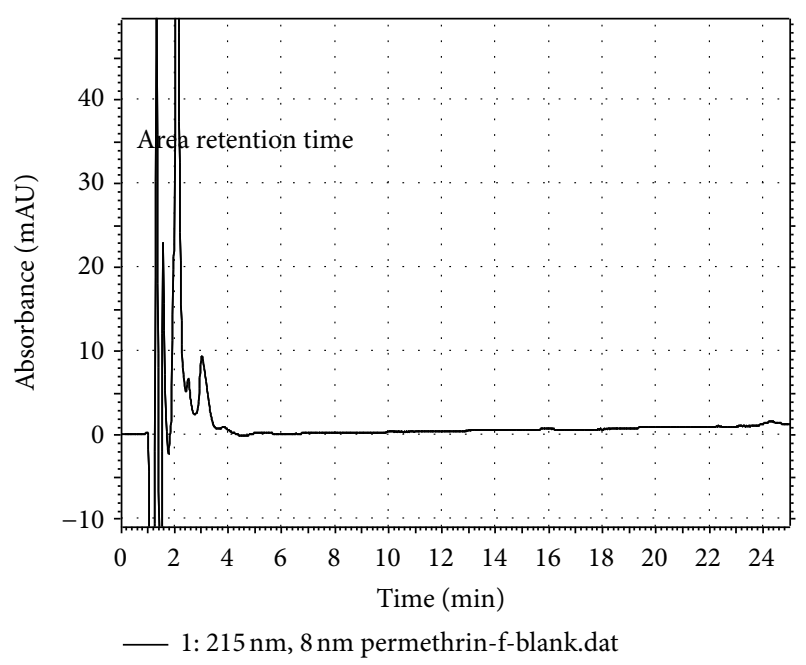

(b)

FIGURE 4: A chromatogram obtained from analyzing of the commercially available cream. The solution contains the target permethrin concentration of $9 \mu \mathrm{g} / \mathrm{mL}$. (b) blank.

TABle 3: Partial and expanded uncertainties associated to the analytical results (expressed as \% relative standard deviation).

\begin{tabular}{lcc}
\hline Uncertainties & Trans-isomer & Cis-isomer \\
\hline$U_{\text {standard }}(\%)$ & 0.07 & 0.07 \\
$U_{\text {calibration }}(\%)$ & 2.70 & 4.04 \\
$U_{\text {precision }}(\%)$ & 1.09 & 1.10 \\
$U_{\text {accuracy }}(\%)$ & 0.25 & 0.27 \\
$U_{\text {expanded }}(\%)$ & 5.84 & 8.39 \\
$U_{\text {expanded }}(\mu \mathrm{g} / \mathrm{mL})$ & 0.39 & 0.19 \\
Concentration $(\mu \mathrm{g} / \mathrm{mL})$ & 6.74 & 2.24 \\
\hline
\end{tabular}

standard error of slope can be used as a parameter with respect to the precision of the regression, as a general acceptance criterion for the linearity performance of the analytical procedure [31]. This parameter should be comparable to the calculated RSD in the evaluation of the precision. In this study, the results obtained for the RSDs of the slopes were $2.14 \%$ and $1.39 \%$ for trans- and cisisomers, respectively, which are comparable to those of the maximum respective precision values of $2.07 \%$ and $1.94 \%$ (Table 2).

The results from the validation of method are summarized in Table 2. The method proved to be precise, as the intra- and interday precision ranged from $0.70 \%-1.90 \%$ and $1.30 \%-2.07 \%$, respectively, for all analytes. These values fulfill the validation criteria of an analytical method designed for quality control of pharmaceutical preparations for which RSD values $<2 \%$ are acceptable [31].

The LOQ is the lowest concentration that can be quantified with acceptable precision and accuracy. The LOQ of permethrin was determined to be $0.5 \mu \mathrm{g} / \mathrm{mL}$, considering the mean accuracy value of $101.18 \%$ and maximum RSD value of $2.07 \%$ (Table 1 ). This value indicates that the proposed method is much more sensitive than what have been reported previously [12-16].

3.3.3. Recovery and Accuracy. The accuracy was evaluated applying the proposed method to the analysis of the in-house mixture of the cream excipients with known amounts of the drug, to obtain solutions at concentrations of $0.5,10,20$, and $50 \mu \mathrm{g} / \mathrm{mL}$. The accuracy was assessed from three replicate determinations and calculated as the percentage of the drug recovered from the formulation matrix. The means and RSD\% obtained for permethrin isomers are shown in Table 2 with a range of $99.53 \%-101.28 \%$ and $99.58 \%-101.42 \%$ for trans-and cis-isomers, respectively, demonstrating that the method is accurate within the desired range. Also, the results obtained from the analysis of pre-assayed creams spiked with different amounts of permethrin stock solution revealed acceptable recoveries with the mean values of 99.79\% and $100.04 \%$ for trans- and cis-isomers, respectively, and $\%$ RSDs $<0.81$. These values document a high recovery in this method.

3.3.4. Robustness. Chromatographic parameters including \% of assay and permethrin isomers resolution were not significantly affected with the slight changes in the chromatographic conditions like alteration in flow rates, $\mathrm{pH}$ of the aqueous solution of mobile phase, and column temperature. Analysis was carried out in triplicate and only one parameter was changed in the experiments at a time. The results of the experimental variables evaluated were within the acceptable deviation $(\mathrm{RSD}<2 \%$ ), and the resolution of permethrin isomers were more than 2 , indicating that the proposed method is robust under the conditions tested.

3.3.5. The Uncertainty of the Method. The expanded uncertainty of the method for quantification of permethrin isomers 
in pharmaceutical preparations was calculated. The results are shown in Table 3.

3.3.6. Application of the Method. The optimized and validated method was applied to the determination of permethrin isomers in marketed creams. The amounts of permethrin isomers in creams were calculated using calibration curve method. (Figure 4(a)) shows typical chromatogram obtained following the assay of Gilaranco creams. The results of the assay undertaken and the calculated uncertainties are shown in Table 3. The value of $99.77 \%$ of label claim indicates that the method is selective for the analysis of permethrin without interference from the excipients used to formulate and produce these creams.

\section{Conclusion}

The aim of this study was to develop a green and specific method for determination of permethrin isomers in pharmaceutical preparations. The method was designed to be specific, selective, sensitive, robust, reproducible, accurate, inexpensive, and easy to perform. The principal advantage of the method is the use of available environmentally friendly solvents and reagents for LC-analyzing and extractions to follow the first principle of green chemistry which emphasizes on waste prevention instead of remediation [18]. To the best of our knowledge, this is the first method which is thoroughly green and reports the metrological parameters in quantification of permethrin in topical preparations. In addition, recycling significantly reduced the mobile phase consumption and made the method economic. Moreover, the method is much more sensitive than the previously reported procedures [12-16].

In conclusion, the newly developed method was successfully performed to simultaneous analysis of permethrin isomers in pharmaceutical preparations, and it can thus be used for routine analysis, quality control, and for studies of the stability of pharmaceutical formulations containing permethrin.

\section{Conflict of Interests}

The authors declared no conflict of interests.

\section{Acknowledgments}

The Authors extend their appreciation to Gilaranco Pharmaceutical Co. for kind donation of permethrin standard and raw material. This work was financially supported by Pharmaceutical Sciences Branch, Islamic Azad University (IAUPS).

\section{References}

[1] K. N. Jones and J. C. English III, "Review of common therapeutic options in the United States for the treatment of pediculosis capitis," Clinical Infectious Diseases, vol. 36, no. 11, pp. 1355-1361, 2003.
[2] E. J. Scollon, J. M. Starr, S. J. Godin, M. J. DeVito, and M. F. Hughes, "In vitro metabolism of pyrethroid pesticides by rat and human hepatic microsomes and cytochrome P450 isoforms," Drug Metabolism and Disposition, vol. 37, no. 1, pp. 221-228, 2009.

[3] D. Tomalik-Scharte, A. Lazar, J. Meins et al., "Dermal absorption of permethrin following topical administration," European Journal of Clinical Pharmacology, vol. 61, no. 5-6, pp. 399-404, 2005.

[4] "Permethrin summary report (1)," Tech. Rep. EMEA/MRL/ 112/96-FINAL, 1998.

[5] I. Gur and R. Schneeweiss, "Head lice treatments and school policies in the us in an era of emerging resistance: a costeffectiveness analysis," PharmacoEconomics, vol. 27, no. 9, pp. 725-734, 2009.

[6] E. Shmidt and J. Levitt, "Dermatologic infestations," International Journal of Dermatology, vol. 51, no. 2, pp. 131-141, 2012.

[7] J. Emer, H. Waldorf, and D. Berson, "Botanicals and antiinflammatories: natural ingredients for rosacea," Seminars in Cutaneous Medicine and Surgery, vol. 30, no. 3, pp. 148-155, 2011.

[8] A. Sobottka and P. Lehmann, "Rosacea 2009: new advances in pathophysiology, clinical staging and therapeutic strategies," Hautarzt, vol. 60, no. 12, pp. 999-1009, 2009.

[9] M. E. Swenor, "Is permethrin 5\% cream effective for rosacea?" Journal of Family Practice, vol. 52, no. 3, pp. 183-184, 2003.

[10] M. Koçak, S. Yağli, G. Vahapoğlu, and M. Ekşioğlu, "Permethrin $5 \%$ cream versus metronidazole $0.75 \%$ gel for the treatment of papulopustular rosacea: a randomized double-blind placebocontrolled study," Dermatology, vol. 205, no. 2-3, pp. 265-270, 2002.

[11] J. Lüssenhop, J. Stahl, S. Wolken, T. Schnieder, M. Kietzmann, and W. Bäumer, "Distribution of permethrin in hair and stratum corneum after topical administration of four different formulations in dogs," Journal of Veterinary Pharmacology and Therapeutics, vol. 35, no. 2, pp. 206-208, 2012.

[12] M. Kazemipour, E. Noroozian, M. Saber Tehrani, and M. Mahmoudian, "A new second-derivative spectrophotometric method for the determination of permethrin in shampoo," Journal of Pharmaceutical and Biomedical Analysis, vol. 30, no. 4, pp. 1379-1384, 2002.

[13] M. A. Shishovska and M. T. Stefova, "Fast and universal HPLC method for determination of permethrin in formulations using $1.8-\mu \mathrm{m}$ particle-packed column and performance comparison with other column types," Journal of Chromatographic Science, vol. 50, no. 1, pp. 43-50, 2012.

[14] M. S. Arayne, N. Sultana, and F. Hussain, "Validated RPHPLC method for determination of permethrin in bulk and topical preparations using UV-vis detector," Journal of Chromatographic Science, vol. 49, no. 4, pp. 287-291, 2011.

[15] E. García, A. García, and C. Barbas, "Validated HPLC method for quantifying permethrin in pharmaceutical formulations," Journal of Pharmaceutical and Biomedical Analysis, vol. 24, no. 5-6, pp. 999-1004, 2001.

[16] R. Manadas, F. Veiga, J. J. Sousa, and M. E. Pina, "Development and validation of an HPLC method for simultaneous determination of cis- and trans-permethrin and piperonyl butoxide in pharmaceutical dosage forms," Journal of Liquid Chromatography and Related Technologies, vol. 22, no. 12, pp. 1867-1876, 1999.

[17] “EPA Hazardous Waste Listings”, 2008. 
[18] R. A. Sheldon, "Fundamentals of green chemistry: efficiency in reaction design," Chemical Society Reviews, vol. 41, no. 4, pp. 1437-1451, 2012.

[19] M. Tobiszewski, A. Mechlińska, and J. Namieśnik, "Green analytical chemistry," Chemical Society Reviews, vol. 39, no. 8, pp. 2869-2878, 2010.

[20] A. dos Santos Pereira, F. David, G. Vanhoenacker, and P. Sandra, "The acetonitrile shortage: is reversed HILIC with water an alternative for the analysis of highly polar ionizable solutes?" Journal of Separation Science, vol. 32, no. 12, pp. 2001-2007, 2009.

[21] D. A. Taylor, "Principles into practice: setting the bar for green chemistry," Environmental Health Perspectives, vol. 118, no. 6, pp. A254-A257, 2010.

[22] J. H. Clark and S. J. Tavener, "Alternative solvents: shades of green," Organic Process Research and Development, vol. 11, no. 1, pp. 149-155, 2007.

[23] M. Tobiszewski and J. Namiesnik, "Direct chromatographic methods in the context of green analytical chemistry," Trac Trends in Analytical Chemistry, vol. 35, pp. 67-73, 2012.

[24] F. Tache and M. Albu, "Specificity of an analytical HPLC assay method of metformin hydrochloride," Revue Roumaine de Chimie, vol. 52, no. 6, pp. 603-609, 2007.

[25] M. Quintela, J. Báguena, G. Gotor, M. J. Blanco, and F. Broto, "Estimation of the uncertainty associated with the results based on the validation of chromatographic analysis procedures: application to the determination of chlorides by high performance liquid chromatography and of fatty acids by high resolution gas chromatography," Journal of Chromatography A, vol. 1223, pp. 107-117, 2012.

[26] P. Konieczka and J. Namieśnik, "Estimating uncertainty in analytical procedures based on chromatographic techniques," Journal of Chromatography A, vol. 1217, no. 6, pp. 882-891, 2010.

[27] S. de Melo Abreu, M. Correia, P. Herbert, L. Santos, and A. Alves, "Screening of grapes and wine for azoxystrobin, kresoxim-methyl and trifloxystrobin fungicides by HPLC with diode array detection," Food Additives and Contaminants, vol. 22, no. 6, pp. 549-556, 2005.

[28] International Organization for Standardization (ISO), Guide To the Expression on Uncertainty in Measurement (GUM), ISO, Geneva, Switzerland, 1995.

[29] M. A. Shishovska, V. P. Trajkovska, and M. T. Stefova, "A simple HPLC method for determination of permethrin residues in wine," Journal of Environmental Science and Health. Part B, vol. 45, no. 7, pp. 694-701, 2010.

[30] K. M. Alsante, A. Ando, R. Brown et al., "The role of degradant profiling in active pharmaceutical ingredients and drug products," Advanced Drug Delivery Reviews, vol. 59, no. 1, pp. 29-37, 2007.

[31] J. Ermer and H. J. Ploss, "Validation in pharmaceutical analysis: Part II: central importance of precision to establish acceptance criteria and for verifying and improving the quality of analytical data," Journal of Pharmaceutical and Biomedical Analysis, vol. 37, no. 5, pp. 859-870, 2005. 

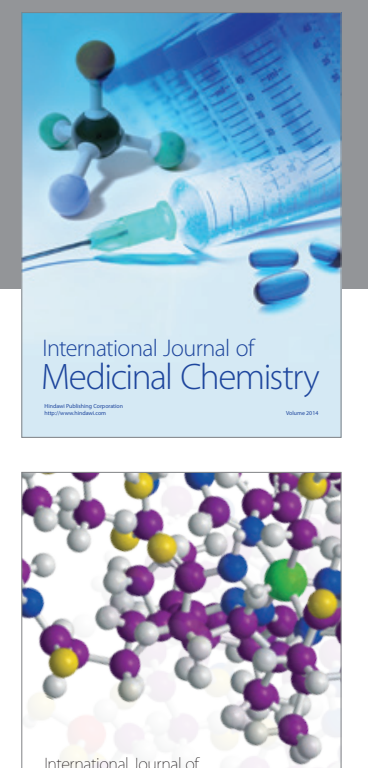

\section{Carbohydrate} Chemistry

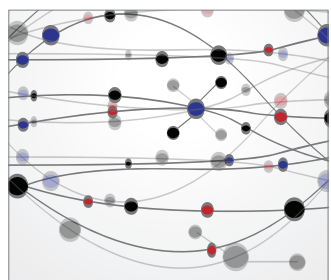

The Scientific World Journal
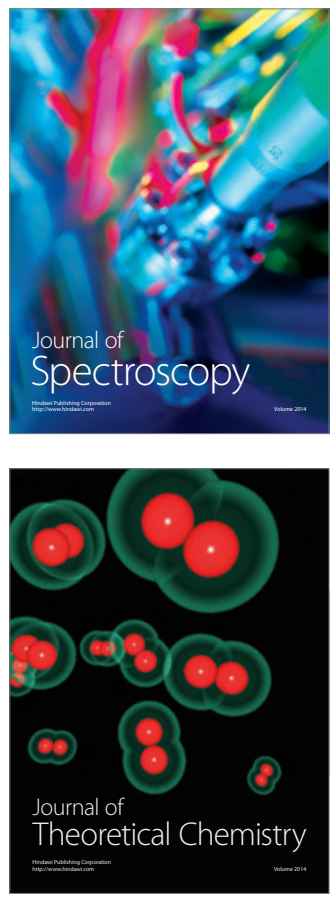
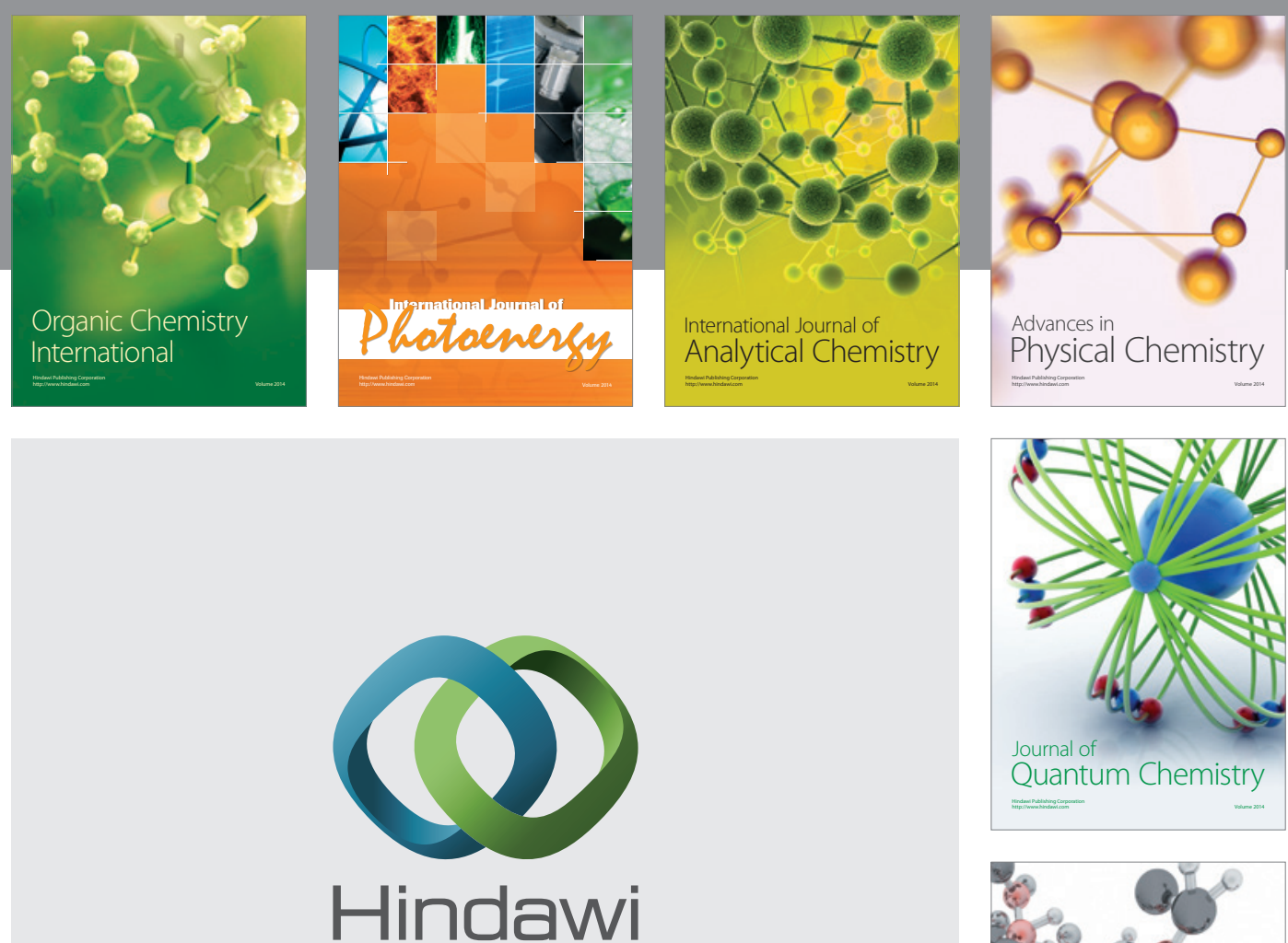

Submit your manuscripts at

http://www.hindawi.com

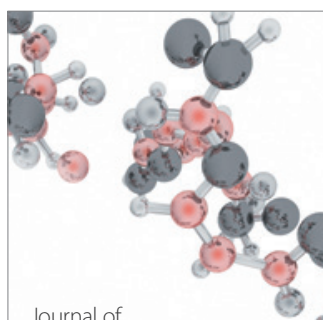

Analytical Methods

in Chemistry

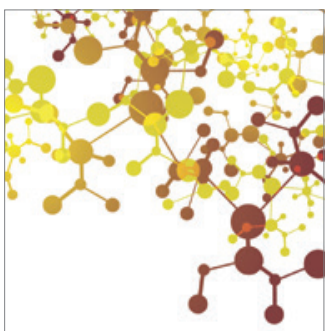

Journal of

Applied Chemistry

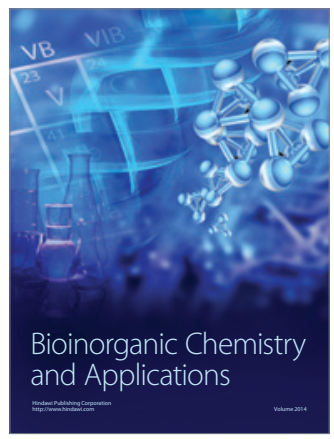

Inorganic Chemistry
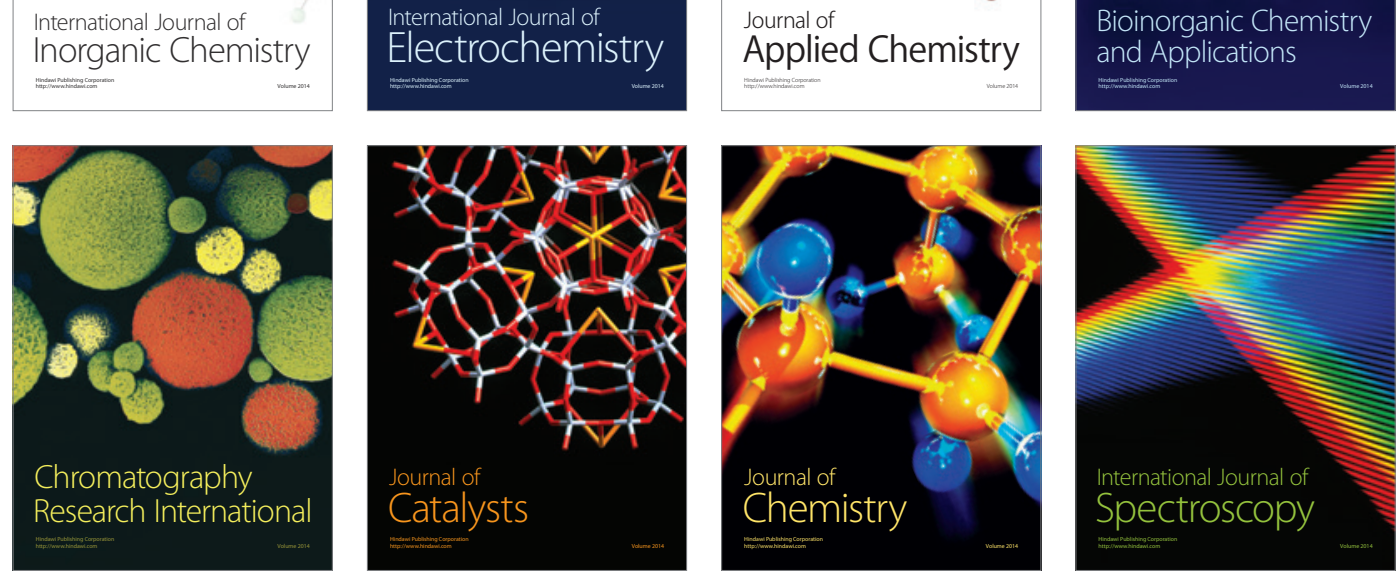